\title{
TRES MIRADAS SOBRE ZAPOTLÁN: YÁÑEZ, RULFO Y ARREOLA
}

\author{
Norma Esther García Meza \\ Universidad Veracruzana (México) \\ normagarcia@uv.mx \\ Daniel Domínguez Cuenca \\ Universidad Veracruzana (México) \\ danieldoc@gmail.com
}

Recibido: 15/01/2019 - Aprobado: 12/06/2019

DOI: doi.org/10.17533/udea.lyl.n76a06

\begin{abstract}
Resumen: Juan José Arreola se caracterizó por establecer vínculos dialógicos con autores pertenecientes a su tradición y con aquellos de tradiciones literarias anteriores. Uno de esos vínculos se construyó con lo dicho por otros dos escritores jaliscienses, sobre un territorio entrañable y decisivo en su conformación como artista: Zapotlán. En 1963, al publicar La feria, y luego en 1971, cuando apareció Tres días y un cenicero, ofreció una mirada artística sobre ese espacio, que condensa otras dos: la de Agustín Yáñez, del 1947, y la de Juan Rulfo, del 1953. El presente artículo busca identificar los sentidos que unen dichas miradas.
\end{abstract}

Palabras clave: mirada; Zapotlán; Agustín Yáñez; Juan Rulfo; Juan José Arreola; memoria.

\section{THREE GLANCES OVER ZAPOTLÁN: YÁÑEZ, RULFO AND ARREOLA}

\begin{abstract}
Juan José Arreola was characterized by establishing dialogical links with authors belonging to his tradition and with those of previous literary traditions. One of these links was built with what was said by two other Jaliscan writers, on an endearing and decisive territory in his conformation as an artist: Zapotlán. Both in 1963 book La feria and in 1971 book Tres días y un cenicero, he offered an artistic look at that space, which condenses two others: that of Agustín Yáñez, from 1947, and that of Juan Rulfo, from 1953. This article identifies the senses that unite these glances.
\end{abstract}

Key words: glance; Zapotlán; Agustín Yáñez; Juan Rulfo; Juan José Arreola; memory.

LINGÜÍSTICA Y LITERATURA 
Yo, señores, soy de Zapotlán [...]

un valle redondo de maíz,

un circo de montañas

sin más adornos que su buen temperamento,

un cielo azul y una laguna que viene y se va

como un delgado sueño [...]

Juan José Arreola

Nunca creí querer tanto a Zapotlán.

En mi pueblo he sufrido mucho y no he podido nunca

pasear por sus calles el estandarte de un gran amor.

¿Me creerá usted si le cuento que algunas noches

sufro por Zapotlán más de lo que sufrí en la más acerba noche

que me proporcionó un desengaño amoroso?

Zapotlán ha resultado para mí la novia más dificil de olvidar...

Juan José Arreola

[...] la memoria es aleatoria y maravillosa,

ensambla todas las cosas del mundo entre sí,

compone las piezas sueltas y las ordena,

aunque sea por un momento,

para hacerlas comprensibles [...]

Juan José Arreola

\section{Yáñez, Rulfo y Arreola: tres escritores jaliscienses}

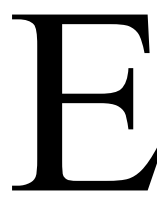

$\mathrm{n}$ la historia literaria mexicana e hispanoamericana es frecuente encontrar juntos a Juan José Arreola (1918-2001) y a Juan Rulfo (1917-1986) y, detrás de ellos, a Agustín Yáñez (1904-1980), su antecesor en el ejercicio literario (Martínez y Domínguez

Michael, 1995, pp. 118-123, 199-208). A los tres los une la destreza artística con la que crearon obras consideradas fundacionales, la capacidad de innovar y transformar valores artísticos existentes en sus respectivas tradiciones y, sobre todo, el lugar donde nacieron: Jalisco, un territorio geográfico determinante en sus particulares visiones del mundo. Al respecto, Hugo Gutiérrez Vega, también jalisciense, afirma que: «Jalisco tiene dos cosmovisiones, la alteña y la abajeña [...]» (García Hernández, 2009) y se refiere a estos tres escritores del siguiente modo:

[...] la novela de Jalisco anda por esos caminos y podemos hacer una teoría sobre las afinidades y diferencias que se dan entre sus grandes creadores, partiendo de la región a la que pertenecieron y pertenecen. Así, diremos que Azuela y Yáñez son alteños, Arreola es abajeño y Rulfo pertenece y trasciende las dos cosmovisiones (Gutiérrez Vega, 2002).

\section{Juan José Arreola: creador de una obra que dialoga}


Siguiendo esta caracterización, puede decirse que el abajeño Juan José Arreola (1918-2001) es creador de una obra que dialoga. Su cosmovisión se caracteriza, entre muchos otros rasgos, por establecer vínculos dialógicos (Bajtín, 1995, pp. 316-317, 334) con autores que pertenecen a su tradición y con aquellos de tradiciones literarias anteriores (Poot, 1992, p. 46). Citarse a sí mismo y citar a los otros de manera literal, de memoria, con humor e ironía o como un ejercicio de parodia, es un recurso frecuente en toda su obra. El juego dialógico de Arreola permite que resuene el discurso del otro en el suyo, que fragmentos o personajes de sus cuentos tengan ecos en su novela, en otros escritos y viceversa. Este rasgo también está presente en su dramaturgia. Elementos del mundo literario de Arreola, algunos de sus héroes y villanos renacen como personajes en sus obras teatrales. Cobran vida sobre la escena adoptando la voz y el cuerpo de otros. Y no sólo la voz de otros, la palabra de otros, sino la música de otros está presente en la obra, en las obras. Canciones populares, canciones de amor, canciones de cuna son evocadas y recuperadas por los personajes.

Uno de esos vínculos dialógicos se gesta con lo dicho por otros dos escritores jaliscienses, sobre un territorio entrañable y decisivo en su conformación como artista: Zapotlán el Grande, Jalisco. En 1963, tras publicar su novela La feria, y en 1971, cuando publica el cuento Tres días y un cenicero, ofrece una mirada artística sobre ese territorio. Se trata de una mirada que condensa otras dos: la de Agustín Yáñez, del año 1947, y la de Juan Rulfo, de 1953. En el presente artículo se hará un intento por identificar los sentidos ${ }^{1}$ que unen estas tres miradas.

\section{El Zapotlán de Arreola}

Zapotlán el Grande, como se sabe, es el espacio físico y poético en el que nació nuestro autor y cuya presencia es notable en casi toda su obra. Su recreación no sólo incorpora un sentido de pertenencia a un espacio específico de la provincia mexicana donde se gestaron sus principales

1. Se hace mención a las coincidencias de puntos de vista que Bajtín identifica en las relaciones dialógicas: «Dos enunciados alejados uno del otro en el tiempo y en el espacio y que no saben nada uno del otro, si los confrontamos en cuanto a su sentido y si manifiestan en esta confrontación alguna convergencia de sentidos (aunque sea un tema parcialmente común, un punto de vista, etc., revelan una relación dialógica)» (Bajtín, 1995, p. 317). 
valores éticos como integrante de una familia y de una comunidad, sino como el lugar donde se gestó su visión artística del mundo y se forjó su condición de escritor.

En textos tan iniciales como «Perspectiva de Zapotlán (Meditación en Ameca)», publicado en el periódico El Occidental, de Guadalajara, Jalisco, el 5 de agosto de 1945 (Arreola, 2002d, pp. 29-33), o El cuervero, cuento que apareció en Varia invención (1949), en el que varios indicios revelan que, a pesar de que no se nombra como tal, ese lugar donde Hilario mata tuzas y hace adobes para sobrevivir es Zapotlán (Arreola, 1998e, pp. 42-51), ya se advierte la importancia que para Arreola tiene este pueblo. En Confabulario (1952) alcanza ya una presencia innegable:

Yo, señores, soy de Zapotlán el Grande. Un pueblo que de tan grande nos lo hicieron Ciudad Guzmán hace cien años. Pero nosotros seguimos siendo tan pueblo que todavía le decimos Zapotlán. Es un valle redondo de maíz, un circo de montañas sin más adornos que su buen temperamento, un cielo azul y una laguna que viene y se va como un delgado sueño. Desde mayo hasta diciembre, se ve la estatura pareja y creciente de las milpas [...] (Arreola, 2002b, p. 7).

Este texto que da inicio a la versión definitiva de su Confabulario en la edición de Joaquín Mortiz (1971), que abre Memoria y olvido de Juan José Arreola (2003) y que se incluyó como epígrafe, constituye una muestra breve y contundente de una «autobiografía de emociones», concepto acuñado por Arreola al referirse al trabajo literario de Marcel Proust (Gómez Haro, 2001, p. 221) y que, evidentemente, puede aplicarse a su propia obra. En ella destaca su origen, describiendo a Zapotlán como ese espacio singular y entrañable en el que nació, para después mencionar en contadas líneas su cuna humilde, su familia compuesta por catorce hermanos, sus raíces genealógicas, sus primeros temores, sus primeros amores, su condición autodidacta, sus múltiples oficios, la decisiva influencia del actor Louis Jouvet en su vida, aquel primer viaje a París, su paso por el Fondo de Cultura Económica y, finalmente, su condición de escritor.

Es en La feria (1963), donde Zapotlán adquiere una presencia central e indiscutible y donde Arreola incluirá una de las descripciones más poéticas de su pueblo natal (Huerta, 1998, p. 59):

Campo de Zapotlán, mojado por la lluvia de junio, llanura lineal de surcos innumerables. Tierra de pan humilde y de trabajo sencillo, tierra de hombres que giran en la ronda anual de las estaciones, que repasan su vida como un libro de horas y que orientan sus designios en las fases cambiantes de la luna. Zapotlán, tierra extendida y redonda, limitada, por el suave declive de los montes, que sube por laderas y barrancos a perderse donde empieza el apogeo de los pinos. Tierra donde hay una laguna soñada que se disipa en la aurora. Una laguna infantil como un recuerdo que aparece y se pierde, llevándose sus juncos y sus verdes riberas [...] (Arreola, 2002a, pp. 57-58). 
Las múltiples voces forjadas en esta novela revelan sus principales rasgos: se trata de un pueblo que originalmente se llamó «Tlayolan» (2002a, p. 63) y luego «Tzapotlán» (p. 64), hasta convertirse en «la segunda ciudad de Jalisco» (p. 10). Sus habitantes se dedican a la agricultura, la alfarería, la carpintería, la herrería y a otros oficios como el de cohetero o zapatero (pp. 7, 16, 51, 125), tiene «todas sus calles empedradas» (p. 10) y sus casas son «feas y macizas» (p. 16). A pesar de los fuertes y frecuentes temblores que ahí se producen, porque el pueblo «está fincado sobre un valle de aluvión y sus tierras fértiles [...] ocultan una colosal falla geológica» (p. 180), su gente no escatima en esfuerzos ni en recursos por hacer cada año la feria de Zapotlán:

Y nosotros salimos ganando porque la feria de Zapotlán se hizo famosa por todo este rumbo. Como que no hay otra igual. Nadie se arrepiente cuando viene a pasar esos días con nosotros. Llegan de todas partes, de cerquitas y de lejos, de San Sebastián y de Zapotiltic, de Pihuamo y desde Jilotlán de los Dolores. Da gusto ver al pueblo lleno de fuereños, que traen sombreros y cobijas de otro modo, guaraches que no se ven por aquí. Nomás al verles la traza se sabe si vienen de la sierra o de la costa. Muchos tienen que quedarse a dormir en los portales, en el atrio de la Parroquia o en la plaza, junto a los puestos de la feria, porque no hay lugar para tanta gente. En todas las casas hay parientes de visita y duermen de a tres y de a cuatro en cada pieza. Los corrales se vacían de gallinas y guajolotes. Y no hay puerco gordo, ni chivo ni borrego que llegue vivo al Día de la Función [...] (p. 19).

El carácter popular y festivo de ese pueblo aparecerá nuevamente en Tres días y un cenicero (1971), pero ahora entretejido a la vital necesidad de celebrar el arte y la cultura, la memoria literaria y artística heredada, que se advierte en la totalidad del cuento y que se ejemplificaron con la declaración festiva del protagonista que celebra el hallazgo de una estatua en el lugar más humilde, desprovisto de prestigio y notoriedad: la laguna de Zapotlán:

¿Cómo viniste aquí? A mi charco de Jalisco. Porque te hallé en el lodo, pallus lacustris, laguna, Mare Nostrum. Mediterráneo en miniatura de Zapotlán. Aquí te hallé y recojo tu fragancia de lodo podrido y me acuerdo. Me acuerdo de niño: quise hallarte. Tesoro indicado en la postura de una garza morena [...] Que yo te encontré oh tú la primera inmortal sobre la tierra recién salida del mar... No en Milo ni en Cirene, sino aquí, lejos del auriñaciense y de los tiempos minoicos. Aquí entre mazorcas y blandos juncos de tule, donde los indios tejen petates, amarran tapeistes y urden sillas frescas con armazón de palo blanco o pintado azul celeste con flores rosas amarillas de cempasúchil, agria flor que huele a fermentos de vida y de muerte como tú... Aquí entre gallaretas, corvejones, sapos, ranas, cucarachas de agua y cucharones. Entre los tepalcates, golondrinos y sambutidores pipiles. Bajo el vuelo rasante de agachonas y el rápido altísimo geométrico de zopilotillos vespéridos. Entre tuzas chatas y murciélagos agudos. Aquí te hallé última forma de soñar despierto (Arreola, 1971, pp. 9-11).

El Zapotlán de La feria también se manifiesta mediante algunos rasgos distintivos que simbolizan la identidad cultural del entorno, como el tule, las güilotas o el nombre del terreno que 
el zapatero y agricultor arrienda para sembrar maíz; y, de manera condensada, cuando el protagonista se asume como autor de esta novela y formula conjetura sobre el origen de la estatua:

Día por completo dedicado a la investigación histórica y erudita. Sin libros de consulta, recurro a la memoria estética y literaria, a unas cuantas notas manuscritas, Por ejemplo: Marcel Bataillon me descubrió mediante Antonio Alatorre, la existencia de Francisco de Sayavedra, el fraile aquel que mencioné en La feria, el que puso su iglesia de Zapotlán aparte [...] Sayavedra trajo la Venus a Zapotlán, y adorándola olvidó su misión. Cuando vinieron a pedirle cuentas, puso su mármol en la laguna, con esperanzas de venirlo a sacar. Pero ya no volvió y sus últimos días fueron de cárcel. Porque escapó arrepentido a las brasas del quemadero. Pero le sacaron al sol sus trapos de converso y le dieron a escoger entre saya verde de judío, o verdadera saya de marrano (1971, pp. 20-22).

Como se puede apreciar, Zapotlán está presente de manera significativa en casi toda la obra de nuestro autor. Es un universo de ficción y un lugar histórico: el pueblo donde Juan José Arreola nació «el 21 de septiembre de 1918 [...] entre pollos, puercos, chivos, guajolotes, vacas, burros, y caballos [el de] las fiestas religiosas [y] los acabos» (Del Paso, 2003, pp. 23, 55). El de «su iglesia sin acabar [...] los festivales de octubre [el] novenario a su patrono, señor San José» (Arreola, 2002d, p. 31). El pueblo habitado por sus seres queridos y los recuerdos de infancia, donde se come: «pan de muertos [...] pinole [...] esquite [...] pozole dulce [...] atole blanco [y] el tamal colado» (Arreola, 2002d, pp. 183, 195-196). Donde se perdió de niño y aprendió a trabajar el campo (Gómez Haro, 2001, pp. 180-181). El pueblo añorado que «prefirió tenderse [...] al borde de las aguas paradas de una laguna y se durmió allí [...] sobre los labios de la tierra [desde que] fray Juan de Padilla, conquistador espiritual, se asomó por primera vez a su valle paradisiaco en el siglo XVI» (Arreola, 2002d, p. 30). El pueblo que los lectores de Arreola conocemos y recordamos porque tiene «una plaza que le dicen de Ameca [...] Una calle ancha y empedrada [...] Por allí desemboca el pueblo en sus campos de maíz» (Arreola, 1999: 78). Pero sobre todo, Zapotlán es el lugar donde la literatura le «entró por los oídos»:

¿Qué cosa es la literatura para mí? Desde hace mucho tiempo tengo ya una opinión formada, que no ha cambiado de manera sustancial [...] la literatura, como las primeras letras, me entró por los oídos. Si alguna virtud literaria poseo, es la de ver en el idioma una materia, una materia plástica ante todo. Esa virtud proviene de mi amor infantil por las sonoridades [...] (Del Paso, 2003, pp. 195,198).

Porque la literatura apareció en su vida fusionada a todo aquello que contaba la gente de Zapotlán: 
[...] a los doce años y en Zapotlán el Grande leí a Baudelaire, a Walt Whitman y a los principales fundadores de mi estilo: Papini y Marcel Schwob, junto con medio centenar de otros nombres más y menos ilustres... Y oía canciones y los dichos populares y me gustaba mucho la conversación de la gente de campo (Arreola, 2002b, pp. 9-10).

En la declaración que aparece en Protagonistas de la literatura mexicana, Juan José Arreola expresará el estrecho y entrañable vínculo con ese pueblo y el papel decisivo que ha tenido en su obra:

En un principio tenía el propósito de rendir homenaje a mi pueblo, al que amo tanto, pero a la hora de escribir volvió a triunfar en mí, no sé por qué artes, el espíritu irónico y sarcástico [...] ¿De dónde sale ese afán de burla y de crítica mordaz? Personalmente yo soy un buen compadre de todo el mundo, pero a la hora de escribir... Lo único que me disculpa es que yo mismo he sido el objeto principal de mis sarcasmos. Pero a pesar de esa especie de pesimismo sonriente o de humor negro quise no desentenderme en Confabulario y en La feria de la realidad social que me rodea. Repetir las palabras de los tlayacanques (los desposeídos de la tierra) tiene para mí el valor de un alegato a favor de su causa [...] Hay también tonos macabros, festivos, bailables, espesos, ágiles, poéticos. En fin, los tonos que, reunidos, configuran la vida de Zapotlán (Carballo, 1986, pp. 485-487)

Pero antes de que este territorio apareciera ficcionalizado o mencionado de manera relevante en diversos momentos, Zapotlán ya había sido mirado y nombrado por otros dos escritores.

\section{Zapotlán bajo la mirada de Yáñez}

En la novela Al filo del agua, de Agustín Yáñez, publicada en 1947, Zapotlán es señalado como la primera plaza a la que envían al párroco Abundio Reyes, una vez concluidos sus estudios en el seminario: «Zapotlán el Grande fue su primer destino, una vez recibido el presbiterado. En la pequeña ciudad - bien poblada, de intensa vida social, de costumbres abiertas, industriosa, rica, con fáciles comunicaciones a Guadalajara y con hegemonía sobre vasta comarca—» (1993, p. 33).

La vivacidad del lugar y el relajamiento de sus pobladores inspiran al recién graduado sacerdote a cumplir una misión sacerdotal comprometida y opuesta a la escrupulosa enseñanza eclesiástica que, inútilmente, se le había tratado de inculcar en el seminario donde, según la versión de sus superiores, siempre fue más proclive a la disipación y a las ideas liberales, más propenso a la broma y al humor que a las tareas piadosas y clericales, más dispuesto a la diversión y la travesura que a la solemnidad de la vida monástica. «Hubiérasele querido más 
piadoso, más reconcentrado, menos inquieto y bromista» (p. 32), dice el narrador y ofrece detalles de los planes que Abundio Reyes piensa realizar en Zapotlán:

[...] el flamante sacerdote vio propicio campo para realizar sus sueños de grandes organizaciones y empresas apostólicas: catecismos para niños y adultos con sentido dinámico en los que rutina y enfado quedaran proscritos; escuelas inspiradas en los métodos más modernos; difusión de la buena prensa; sociedades de jóvenes de uno y otro sexo, de damas, de obreros y patronos, encaminadas a la acción, como las que florecían en algunos países de Europa. Rápidamente se relacionó con las familias más distinguidas e inspiró confianza a los hombres tachados de liberales, despertando suspicacias, la del párroco en primer término, a quien parecieron 'modernistas' y peligrosos los planes de trabajo propuestos por su nuevo ministro; no había que hacer novación en la vida de la feligresía, ni hacerse ilusiones con procedimientos extraños al ritmo religioso tradicional en la Arquidiócesis; tampoco este muchacho inexperto, efusivo, debía exponerse a los riesgos de la vida social, en una población de preferencias profanas (p. 33).

Esos planes o sueños son completamente opuestos a la práctica sacerdotal derivada de la doctrina cristiana opresiva y dominante que prevalece en la región. Por ello, un año después de la llegada del Padre Reyes a Zapotlán, se tramita su traslado al pueblo de mujeres enlutadas, «ese pueblo sin categoría, de extraño nombre y sin referencia en los mapas de la República» (p. 33), donde transcurre la historia de Al filo del agua:

El párroco fue apartándolo del trato civil, encomendábale actividades rurales y le quitó la ocasión de llevar a la práctica el más pequeño de sus proyectos, la idea de renovar los métodos catequísticos. Al cabo, el Padre Reyes tuvo sobre sí la predisposición franca del párroco, y el resultado fue que antes del año, en pésima situación económica, recibiera oficio de transladarse a un pueblo desconocido, en rumbo diametralmente opuesto de la Arquidiócesis, con difícil acceso por caminos de herradura, punto menos que intransibles en ese tiempo de lluvias en que se le comunicó el cambio (p. 33).

Y Zapotlán se convierte, entonces, en un motivo de nostalgia para el Padre Reyes que marcará un antes y un después en su vida sacerdotal. El narrador da detalles de cómo el carácter del pueblo influye en el ánimo y la conducta del joven sacerdote:

El carácter del pueblo, a su vez, impuso nuevos cauces a las facultades y preferencias del sacerdote: no le pasó por la cabeza organizar veladas literarias musicales, representaciones dramáticas, quermeses, paseos, a que tan aficionado era en el Seminario y que le acarrearon en Zapotlán el disgusto del párroco y las críticas de muchos fieles graves. Se ha concretado a formar un coro de hombres y muchachos para servicios estrictos de la iglesia; trata lo menos posible a las mujeres; cuando entra a las casas y a los comercios, va siempre con misión estricta, de acuerdo con el cura, y si parece distraerse charlando sabrosamente - lo que no deja de serle criticado, en especial cuando habla con personas como el director político, el boticario, el huizachero y otros sospechosos a la ortodoxia y pureza moral comunes-, es que algunos asuntos requieren rodeos y hay remedios que necesitan 
jarabe. Así el Padre Abundio lleva ya ocho años en el pueblo; sólo dos veces fue a la capital del Estado y sede archiepiscopal, en viaje de negocios (p. 35).

Ese pueblo donde ahora vive el padre Reyes — «Pueblo cerrado. Pueblo de mujeres enlutadas. Pueblo solemne»- (Yáñez, 1993, pp. 5-6), contrasta radicalmente con el Zapotlán de su memoria al que sus amigos le insisten en volver:

[...] inútilmente sus amistades de Zapotlán le invitan a que vaya en vacaciones, que tampoco ha querido disfrutar. Hace tres años recibió cambio a Lagos; con su anuencia, el señor cura Martínez y otros vecinos transladáronse a Guadalajara y lograron la anulación de las órdenes. — «No sabemos qué bebedizo te hayan dado en esos andurriales»-dícenle amigos interesados por sacarlo de aquí mejorándolo. Últimamente supo que se trataba de conseguirle una capellanía dentro de la capital y escribió para que cesasen las gestiones (1993, p. 35).

Más allá de que Zapotlán sea referencia de una existencia distinta a la que ahora experimenta el sacerdote, lo interesante es que todos esos atributos que ha formulado el narrador: la «intensa vida social», las «costumbres abiertas», la presencia de «hombres tachados de liberales», con una «población de preferencias profanas», donde es posible realizar «veladas literarias musicales, representaciones dramáticas, quermeses, paseos», serán algunos de los rasgos distintivos de un pueblo llamado Zapotlán en una novela de nombre festivo que se publicará dieciséis años después de Al filo del agua: La feria.

\section{Zapotlán bajo la mirada de Rulfo}

Antes, en 1953, el protagonista de La Cuesta de las Comadres, uno de los cuentos incluidos en El Llano en llamas, de Juan Rulfo, al recordar cómo y cuándo mató a Remigio Torricos, dice que fue una noche de luna llena, en octubre, justo cuando en un pueblo vecino se celebraban las fiestas anuales. Ese pueblo es Zapotlán, un lugar que, desde la cuesta donde está sentado el personaje, era posible ver con claridad:

Antes, desde aquí, sentado donde ahora estoy, se veía claramente Zapotlán. En cualquier hora del día y de la noche podía verse la manchita blanca de Zapotlán allá lejos. Pero ahora las jarillas han crecido muy tupido y, por más que el aire las mueve de un lado para otro, no dejan ver nada de nada (Rulfo, 2008, p. 45).

En el cuento de Rulfo, Zapotlán es recreado como un espacio en el que sus habitantes no ven «con buenos ojos» a quienes viven o vivían en la Cuesta de las Comadres:

LINGÜÍSTICA Y LITERATURA 
Los difuntos Torricos siempre fueron buenos amigos míos. Tal vez en Zapotlán no los quisieran pero, lo que es de mí, siempre fueron buenos amigos, hasta tantito antes de morirse. Ahora eso de que no los quisieran en Zapotlán no tenía ninguna importancia, porque tampoco a mí me querían allí, y tengo entendido que a nadie de los que vivíamos en la Cuesta de las Comadres nos pudieron ver con buenos ojos los de Zapotlán. Esto era desde viejos tiempos (2008, p. 43).

Los habitantes de la Cuesta de las Comadres que, poco a poco, abandonaron esa tierra, preferían dar un rodeo para no pasar por Zapotlán:

De tiempo en tiempo, alguien se iba; atravesaba el guardaganado donde está el palo alto, y desaparecía entre los encinos y no volvía a aparecer ya nunca. Se iban, eso era todo [...] No se iban para el lado de Zapotlán, sino por este otro rumbo, por donde llega a cada rato ese viento lleno del olor de los encinos y del ruido del monte. Se iban callados la boca, sin decir nada ni pelearse con nadie (p. 44).

Zapotlán es perfilado como un pueblo en el que se corren riesgos, según se desprende de la siguiente declaración:

Comenzando porque Odilón no debía haber ido a Zapotlán. Eso tú lo sabes. Tarde o temprano tenía que pasarle algo en ese pueblo, donde había tantos que se acordaban mucho de él. Y tampoco los Alcaraces lo querían. Ni tú ni yo podemos saber qué fue a hacer él a meterse con ellos (pp. 50-51).

Pero también como un sitio al que es posible ir de paseo: «el mitote de ir a pasearse a Zapotlán» (p. 45), o de compras: «Yo me había comprado una frazada. Vi que se venían muy aprisa los fríos y el gabán que yo tenía estaba ya todito hecho garras, por eso fui a Zapotlán a conseguir una frazada» (p. 49). Lo más importante es que aparece como un pueblo que celebra sus fiestas:

Me acuerdo que eso pasó allá por octubre, a la altura de las fiestas de Zapotlán. Y digo que me acuerdo que fue por esos días, porque en Zapotlán estaban quemando cohetes, mientras que por el rumbo donde tiré a Remigio se levantaba una gran parvada de zopilotes a cada tronido que daban los cohetes. De eso me acuerdo (p. 51).

El protagonista-narrador ha dicho: «eso pasó allá por octubre / a la altura de las fiestas de Zapotlán / en Zapotlán estaban quemando cohetes», y es inevitable no recordar, al escucharlo, el párrafo que cierra la novela de Arreola:

Nadie podía haber previsto lo que sucedió esta noche, la última de la feria, a las doce en punto. Todo el pueblo estaba reunido en la plaza, rodeando el inmenso castillo pirotécnico, orgullo de todos nosotros y símbolo de la fiesta, erigido a un costado de la Parroquia por más de cincuenta obreros bajo las órdenes de don Atilano el cohetero. Nunca habíamos visto algo más bello y majestuoso. Justamente 
en el momento en que iba a darse la orden para que fuera encendido irrumpió una pequeña banda de desalmados. Nadie pudo darse cuenta de quiénes eran, ni cuántos. Iban vestidos de Viejos de la danza, con máscaras de diablo. Unos llevaban teas encendidas, otros baldes y machetes, otros más, pistolas que disparaban al aire. En cosa de instantes, bañaron de petróleo la base de las cuatro torres que sostenían la plataforma desde donde se alzaba el castillo principal, y les prendieron fuego. La gente cercana huyó despavorida porque el combustible se derramó por el empedrado. La llamarada pronto se levantó al cielo, más alta que la Parroquia [...] En vez de arder parte por parte y en el orden previsto por don Atilano, ya se imaginarán lo que pasó. El estallido fue general y completo, como el de un polvorín. Los buscapiés se fueron por todas partes, sin ton ni son, y sobre la multitud cayó una verdadera lluvia de fuego por fortuna artificial [...] (Arreola, 2002a, p. 182).

¿Es esa «lluvia de fuego», con cohetes que truenan «sin ton ni son», lo que el protagonistanarrador del cuento de Rulfo mira desde la Cuesta de las Comadres la misma noche en que mató a Remigio Torricos? No se tiene respuesta para esta pregunta que, seguramente, servirá como hipótesis para futuras investigaciones, por lo pronto sólo se puede subrayar lo que es considerado como evidente: que ese carácter festivo, señalado por el protagonista-narrador del cuento, será el eje central de la recreación artística que Juan José Arreola realizará de su pueblo natal en la novela La feria, publicada diez años después de El Llano en llamas. ${ }^{2}$

Pero el vínculo entre el cuento de Rulfo y la novela de Arreola no sólo se advierte en las referencias comentadas. El perfil violento de Odilón, que los lectores conocen desde la primera mención de él y su hermano en voz del protagonista-narrador (Rulfo, 2008, p. 43), está presente en uno de los personajes de La feria. La mención es para Odilón, el sobrino de don Abigail, que tiene fama de «burro manadero» (Arreola, 2002a, p. 103) y que presume de quitarle «el orgullo del zalate» (2002a, p. 103) a una prostituta y «los seis centavos» (pp. 107, 153) a una de las Hijas de María (p. 107). El mismo que «tiene una novia en cada pueblo» (p. 104), que se robó «una muchacha en San Gabriel» y que está «amenazado de muerte» (p. 104).

El Odilón de «La Cuesta de las Comadres» es «duro de entendederas» (Rulfo, 2008, p. 49), le gusta «encararse con todos [y es un] sinvergüenza» (2008, p. 49), rasgos similares a los que definen la actuación del Odilón de La feria:

Como no podía meterse a la tienda con todo y caballo, ni tenía ganas de bajarse, Odilón, medio bebido, gritó desde la banqueta frente a la tienda de don Salva:

- Te vengo a decir que me voy...

Chayo, roja y avergonzada, se quedó como si no oyera, dándole vueltas a una bola de estambre.

2. O quince años después, si se considera el siguiente dato que ofreció Rafael Olea Franco: «La Cuesta de las Comadres [...] se publicó por vez primera en febrero de 1948, en la revista América, la cual desde varios años atrás venía difundiendo algunos cuentos de Rulfo» (2018, p. 163). 
- No te pongas así. Me voy pero vuelvo. Dime adiós, pero con gusto, para que me acuerde mucho de ti...

-Yo no sé dónde tiene la cabeza Chayo. Una muchacha tan decente, Hija de María, y haciéndole caso a Odilón. Una de dos, o la deja colgada, o le quita los seis centavos, y si es que no se los ha quitado уа...

- ¿Y qué tal si se casa con ella?

-Qué casarse ni qué ojo de hacha. Él tiene una novia formal en Guadalajara, y aquí y en otros pueblos nomás anda buscando muchachas que le hagan el áijale. Dicen que se mete con las criadas de su casa y hasta con las hijas de sus mozos. A todas les dice que va a casarse con ellas. ¿Y pasa usted a creer que todas estas ignorantes se tragan el paquete? Y allí se quedan, como burras enquelitadas, esperando que vaya a pedirlas... (Arreola, 2002a, p. 104, 107).

¿Ese Odilón «medio bebido» que, en el Zapotlán de La feria, se dedica a buscar «muchachas que le hagan el áijale», es el mismo que en el cuento muere después de que «le escupió un trago de mezcal en la cara a uno de los Alcaraces», el que «no debía haber ido a Zapotlán» porque «tarde o temprano tenía que pasarle algo en ese pueblo?» (Rulfo, 2008, pp. 50-51). No es posible asegurarlo pero Arreola es un auténtico confabulador que constantemente pone a prueba a sus lectores, proponiéndole nuevas rutas por las cuales reconocer el tránsito o tránsitos de frases, personajes, pasajes enteros que traslada de un texto a otro sin previo aviso, así que el Odilón de La feria, con ese perfil tan similar al del Odilón que se pasea y muere en el Zapotlán de $L a$ Cuesta de las Comadres bien puede ser un guiño, una travesura de Arreola, que rinde así un malicioso homenaje a Rulfo, de quien fue su primer lector (Del Paso, 2003, pp. 175-176 y Alatorre, 2005, p. 50).

\section{Comentario final: infancia, convivencia, lectura y memoria}

Evidentemente, estos tres escritores jaliscienses se conocían. En el artículo «Historia de los dos que soñaron: Yáñez y Arreola», Sara Poot recupera algunas de las célebres anécdotas compartidas por Yáñez y Arreola - y narradas por éste en El último juglar-, que hacen evidente «un pacto de amistad y una complicidad no exenta de humor» (2006, p. 27), entre ambos escritores. Acerca de la amistad entre Arreola y Rulfo existen múltiples publicaciones, por lo que se hará mención, a modo de ejemplo, únicamente a dos declaraciones del propio Arreola. La primera, que aparece también en El último juglar, señaló lo siguiente: 
Arturo Rivas Sainz me presentó a Juan Rulfo en casa de Lupe y Xóchitl Díaz de León. Esto ocurrió entre marzo y abril de 1945 [...] Desde entonces mantuve una larga amistad con Juan, que a veces se interrumpía y otras veces algunos amigos y enemigos pretendían, sin lograrlo, enemistarnos y distanciarnos, con argumentos dudosos como aquel de que yo era un afrancesado y Juan un nacionalista (Arreola, 1998, pp. 211-213).

La segunda, está registrada en ¿Te acuerdas de Rulfo, Juan José Arreola? Entrevista en un acto, de Vicente Leñero, y que, por su importancia, se cita en extenso:

Antes de encontrarnos Juan Rulfo y yo, había antecedentes infantiles que mi hermano Rafael recuerda y yo no. Mi encuentro real con Rulfo ocurrió en 1943, al final, sobre todo a principios de 1944, cuando yo estaba a punto de casarme [...] No, no, no. Lo conozco de antes porque su familia, sus padres, su madre, sus tíos, estuvieron en Zapotlán cuando la Revolución Cristera. Éramos chicos... Mi hermano Rafael sostiene: «Mira, ¿sabes dónde vivieron los Pérez Rulfo? ¡En Zapotlán!» A dos puertas de mi casa, que todavía existe: la casa de mis hermanos [...] No. Nos conocimos, pero imposible recordarlo... Jugábamos en la calle, era nuestra calle [...] Entonces: la infancia está perdida en la memoria. Y es cierto que Juan estuvo de niño, a los diez años, como Agustín Yáñez antes, en Zapotlán... Zapotlán era una plaza fuerte: Ciudad Guzmán: un valle de montañas con dos fuertes muy bien guardados: la garita de Santa Catarina, yendo a Guadalajara, es decir, hacia Sayula: la garita de Santa Catarina, entre Zapotlán y Sayula. Y por el otro lado: la garita de Huescalapa, con salida hacia Colima. Esa era la cosa, ¿verdad?... Entonces, en la Revolución, desde la primera, y desde la Cristera a la última, Ciudad Guzmán era una plaza fuerte y bien guardada. Y familias de todo el sur de Jalisco y de Colima venían a resguardarse al Valle de Zapotlán, al pie de los volcanes: el Nevado de Colima y el del Fuego [...] Entonces, ese es el pasado remoto. Pero el encuentro real, auténtico, ocurre a fines de 1943 [...] Y entonces, después de la revista Eos, que es 1943, a fines del año, y a principios de 44, sucede el encuentro con Juan Rulfo [...] Y aquí viene ya lo que me importa. Fue Adalberto o Arturo quien me presentó con Juan Rulfo en la farmacia de las hermanas Díaz de León, en las calles de Hidalgo y Tolsá, o Morelos y Tolsá. Ahí [...] En Guadalajara, claro... (Leñero, 2002, pp. 14-17).

\section{Conclusiones}

Para concluir, sólo es posible subrayar que, más allá de la convivencia de los tres jaliscienses, lo más importante desde el punto de vista artístico es que conocían sus obras (Poot, 2006, p. 29 y Del Paso, 2003, pp. 175-176). Y Arreola, perspicaz lector y diestro escritor que ejercitaba el arte de la memoria (Arreola, 2002c, pp. 25-26), tomó la esencia de lo leído en la novela de Yáñez y en el cuento de Rulfo y creó, desde su particular visión del mundo, desde su ser alteño, un nuevo sentido de Zapotlán ${ }^{3}$ : un sentido festivo y popular, colmado de burla y humor, que condensa las tres miradas sobre Zapotlán y con el que, a partir de la publicación de La feria y Tres días y un

3. «Un sentido descubre sus profundidades al encontrarse y al tocarse con otro sentido, un sentido ajeno: entre ellos se establece una suerte de diálogo que supera el carácter cerrado y unilateral de estos sentidos» (Bajtín, 1995, p. $352)$.

LINGÜÍSTICA Y LITERATURA

ISSN 0120-5587

E-ISSN 2422-3174

N. ${ }^{o} 76,2019,139-153$ 
cenicero, su pueblo natal quedó encumbrado, ya para siempre, en la literatura mexicana e hispanoamericana.

\section{Referencias bibliográficas}

1. Alatorre, A. (2005). La persona de Juan Rulfo, en Revista Casa del Tiempo, Vol. VIII, Época III, No. 82, noviembre. México: Universidad Autónoma Metropolitana.

2. Arreola, J. J. (2002a). La feria. México: Joaquín Mortiz.

3. Arreola, J. J. (2002b). Confabulario. México: Joaquín Mortiz.

4. Arreola, J. J. (2002c). Inventario. México: Diana-Conaculta.

5. Arreola, J. J. (2002d). Prosa dispersa. México: Lecturas Mexicanas.

6. Arreola, J. J. (1998e). Varia invención. México: Joaquín Mortiz.

7. Arreola, J. J. (1999) Confabulario. México: Planeta-Conaculta.

8. Arreola, J. J. (1971). Palindroma. México: Joaquín Mortiz.

9. Arreola, O. (1998). El último juglar, Memorias de Juan José Arreola. México: Diana.

10. Bajtín, M. (1995). Estética de la creación verbal (Trad. Tatiana Bubnova). México: Siglo XXI.

11. Carballo, E. (1986). Protagonistas de la literatura mexicana. México: Lecturas Mexicanas No. 3, Ediciones del Ermitaño/SEP.

12. Del Paso, F. (2003). Memoria y olvido de Juan José Arreola. México: Fondo de Cultura Económica.

13. García Hernández, A. (2009). La serenidad y el asombro, entrevista a Hugo Gutiérrez Vega. La Jornada Semanal, 20 de diciembre, Núm. 772. Recuperado de http://www.jornada.unam.mx/2009/12/20/sem-arturo.html

14. Gómez Haro, C. (2001). Arreola y su mundo. México: Alfaguara-Conaculta-INBA.

15. Gutiérrez Vega, H. (2002). Arreola, La feria, los abajeños y los alteños (I), Bazar de asombros, La Jornada Semanal, 31 de marzo. Recuperado de http://www.jornada.com.mx/2002/03/31/sem-bazar.html

16. Huerta, D. (1998). Doce viñetas para Arreola, en Revista Tierra Adentro, Núm. 93, agostoseptiembre. México: Secretaría de Cultura. 
17. Leñero, V. (2002). ¿Te acuerdas de Rulfo, Juan José Arreola? Entrevista en un acto. México: Ficción, Universidad Veracruzana.

18. Martínez, J. L. y Domínguez Michael, Ch. (1995). La literatura mexicana del siglo XX. México: Consejo Nacional para la Cultura y las Artes.

19. Olea Franco, R. (2018). Borges y Rulfo: otro diálogo posible, Nueva Revista de Filología Hispánica (NRFH), XIV, Núm. 1. México: Centro de Estudios Lingüísticos y Literarios. El Colegio de México. 153-181.

20. Poot Herrera, S. (1992). Un giro en espiral. El proyecto literario de Juan José Arreola. México: Universidad de Guadalajara.

21. Poot Herrera, S. (2006). Historia de los dos que soñaron: Yáñez y Arreola, Revista Casa del Tiempo, número 87. México: UAM. 27-30.

22. Rulfo, J. (2008). El Llano en llamas (17 ${ }^{\mathrm{ma}}$ edición). Madrid: Ediciones Cátedra, Colección Letras Hispánicas.

23. Yáñez, A. (1993). Al filo del agua. (Edición crítica). En A. Azuela (Coord.). México: Colección Archivos; 22, Consejo Nacional para la Cultura y las Artes/Unesco. 